\title{
Effect of Papaverine on Left Internal Mammary Artery Flow: Topical Spraying versus Perivascular Injection Method
}

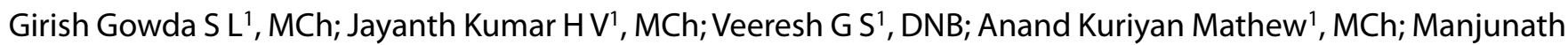
Cholenahally Nanjappa ${ }^{1}$, DM

DOI: $10.21470 / 1678-9741-2019-0126$

\begin{abstract}
Objective: To analyze two techniques of papaverine application, topical spray on the harvested left internal mammary artery (LIMA) and perivascular injection, to find out their ability to improve LIMA flow.

Methods: Forty patients were randomized into two groups. In Group 1, papaverine was sprayed on the harvested pedunculated LIMA. In Group 2, papaverine was delivered into the perivascular plane. Drug dosage was the same for both groups. LIMA flow was measured 20 minutes after applying papaverine. Blood flow was recorded for 20 seconds and flow per minute was calculated. The systemic mean pressures were maintained at $70 \mathrm{mmHg}$ during blood collection. The data collected was statistically evaluated and interpreted.
\end{abstract}

Results: The LIMA blood flow before papaverine application in the Group 1 was $51.9 \pm 13.40 \mathrm{ml} / \mathrm{min}$ and in Group 2 it was $55.1 \pm 15.70 \mathrm{ml} / \mathrm{min}$. Statistically, LIMA flows were identical in both groups before papaverine application. The LIMA blood flow, post papaverine application, in Group 1 was $87.20 \pm 13.46 \mathrm{ml} / \mathrm{min}$ and in Group 2 it was $104.7 \pm 20.19 \mathrm{ml} / \mathrm{min}$. The Group 2 flows were statistically higher than Group 1 flows.

Conclusion: Papaverine delivery to LIMA by the perivascular injection method provided statistically significant higher flows when compared to the topical spray method. Hence, the perivascular delivery of papaverine is more efficient than the spray method in improving LIMA blood flow.

Keywords: Papaverine. Mammary Artery. Biometry, Infections. Vasodilator Agents.

\begin{tabular}{ll}
\hline Abbreviations, acronyms \& symbols \\
\hline CABG $\quad=$ Coronary artery bypass grafting \\
IV $\quad=$ Intravenous \\
LIMA $\quad=$ Left internal mammary artery \\
NTG $\quad=$ Sodium nitroprusside \\
\hline
\end{tabular}

\section{INTRODUCTION}

The left internal mammary artery (LIMA) graft is the most commonly used arterial graft in coronary artery bypass grafting $(C A B G)^{[1]}$. LIMA spasm is an undesirable complication during LIMA harvesting. LIMA spasm can lead to immediate and late morbidity and mortality of the patient after $\mathrm{CABG}^{[2]}$. Various drugs and precautions are used during LIMA harvesting to prevent spasm. Many studies have shown papaverine to increase blood flow compared to control[3-6], and sodium nitroprusside (NTG) has also been used in few studies and found to be effective in relieving LIMA spasm and improving LIMA flow ${ }^{[7,8]}$. Intraluminal instillation of papaverine has shown to cause mechanical injury to the lumen of the mammary artery, causing dissections and medial disruption ${ }^{[9,10]}$. Hence, perivascular application of papaverine is the safest method of papaverine delivery. We use a combination of papaverine and NTG to prevent LIMA spasm and to improve the flow. Papaverine can be applied perivascularly by two methods: topical spray and perivascular injection. We have evaluated these two techniques to find out their ability to improve the LIMA flow.

\section{METHODS}

Forty patients who underwent CABG were randomized into two groups. The preoperative risk factors and patients'
'Department of Cardiothoracic and Vascular Surgery, Sri Jayadeva Institute of Cardiovascular Sciences and Research, Bangalore, Karnataka, India.

This study was carried out at the Sri Jayadeva Institute of Cardiovascular Sciences and Research, Bangalore, Karnataka, India.
Correspondence Address:

Girish Gowda S L

(iD) https://orcid.org/0000-0002-7772-9516

Department of Cardiothoracic and Vascular Surgery, Sri Jayadeva Institute of

Cardiovascular Sciences and Research, Bangalore, Karnataka, India.

Zip Code: 560069

E-mail: gowda1212@yahoo.co.in 


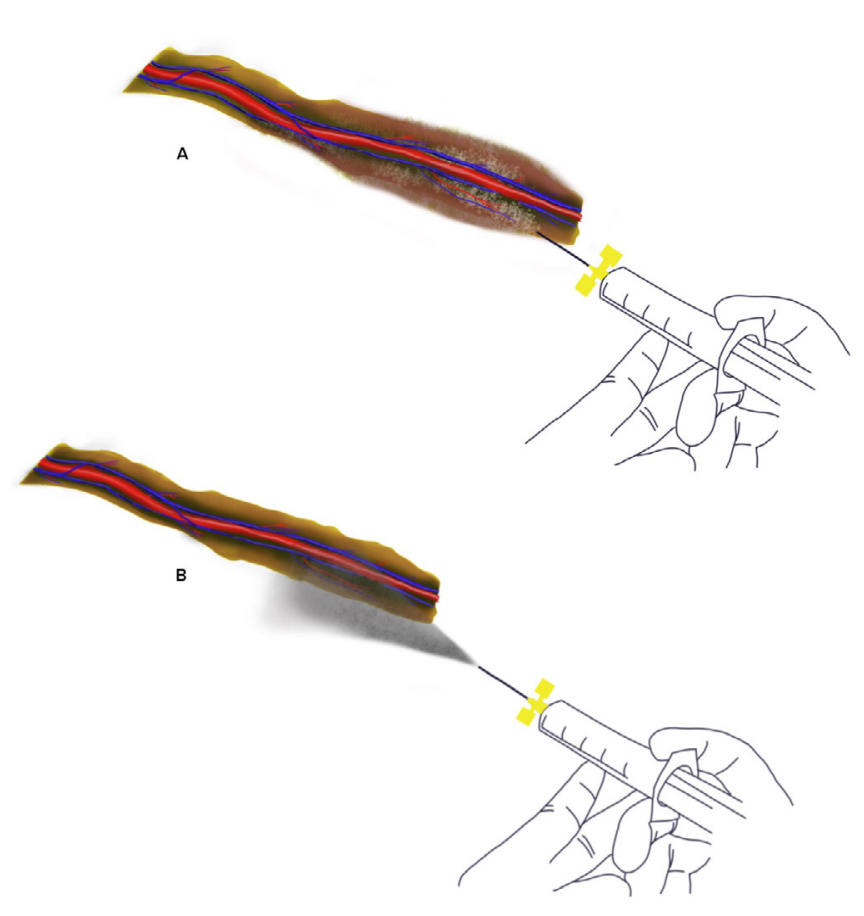

Fig. 1 - Diagrammatic representation of two different methods of papaverine delivery adopted in this study. A) Perivascular method; B) spray method.

characteristics were statistically the same for both groups. Midline sternotomy was done in all patients followed by LIMA harvesting with a wide pedicle up to bifurcation. LIMA was harvested by a single surgeon with low power electrocautery (30 W) in fulgurate mode. Major branches were controlled with hemoclips. Systemic heparinization was done with 400 units/kg heparin dose and LIMA was transected three minutes after the heparin dose administration. LIMA blood flow was collected for 20 seconds and flow per minute was calculated. After measuring the blood flow, LIMA was clipped at the distal end. Papaverine solution was prepared by adding $30 \mathrm{mg}$ papaverine in $100 \mathrm{ml}$ of normal saline making it $0.3 \mathrm{mg} / \mathrm{ml}$. In Group 1, papaverine was sprayed topically from a distance of 5 to 10 centimeters to the harvested pedunculated LIMA using a blunt tipped intravenous
(IV) cannula (Vasofix Centro 24G) (Figure 1B). In Group 2, papaverine was delivered by perivascular injection using a blunt tipped IV cannula (Vasofix Centro 24G) (Figure 1A), taking precaution not to injure LIMA. Drug dosage was the same for both groups. Figure 1 shows a diagrammatic representation of the two different methods of papaverine delivery adopted in this study. The harvested LIMA was wrapped with a gauze soaked in the solution and was placed in the left hemithorax for 20 minutes. LIMA flow was measured 20 minutes after applying papaverine. Blood flow was recorded for 20 seconds and flow per minute was calculated. The systemic mean pressures were maintained at $70 \mathrm{mmHg}$ during blood collection. The data collected was statistically evaluated and interpreted.

\section{Statistical Analysis}

Continuous variables are reported as mean \pm standard deviation and were compared using the t-test for normal distributions. The t-test for one mean and comparison of the mean was done. A pilot study was done, and the sample size was calculated. Student's paired $t$-test and unpaired $t$-test were done, and reported $P$-values of $<0.05$ were considered statistically significant. Statistical analysis was performed with MedCalc statistical software.

\section{RESULTS}

The LIMA blood flow before papaverine application in Group 1 was $51.9 \pm 13.40 \mathrm{ml} / \mathrm{min}$ and in Group 2 it was $55.1 \pm 15.70 \mathrm{ml} /$ min. Statistically, LIMA flows were identical in both groups before papaverine application. The LIMA blood flow after papaverine application in Group 1 was $87.20 \pm 13.46 \mathrm{ml} / \mathrm{min}$ and in Group 2 it was $104.7 \pm 20.19 \mathrm{ml} / \mathrm{min}$ (Table 1). The unpaired t-test showed that Group 2 flow was statistically higher than Group 1 flow $(P<0.005)$. Figure 2 demonstrates the graph depicting the distribution of flow in Groups 1 and 2 after papaverine application.

\section{DISCUSSION}

The LIMA to left anterior descending artery anastomosis is the most commonly performed bypass grafting. LIMA is an important and a vital graft due to its inherent ability to last for long time when compared to other graft conducts. LIMA spasm is a well-recognized complication encountered after LIMA

Table 1. Left internal mammary artery flow measurements and their statistical analysis.

\begin{tabular}{l|c|c|c}
\hline & $\begin{array}{c}\text { Pre-papaverine application flow } \\
\text { (ml/min) }\end{array}$ & $\begin{array}{c}\text { Post-papaverine application flow } \\
\text { (ml/min) }\end{array}$ & Student's paired t-test \\
\hline Group 1 & $51.9 \pm 13.40$ & $87.20 \pm 13.46$ & $<0.05$ (significant) \\
\hline Group 2 & $55.1 \pm 15.70$ & $104.7 \pm 20.19$ & $<0.05$ (significant) \\
\hline Student's unpaired t-test & 0.4923 (not significant) & $<0.05$ (significant) & \\
\hline
\end{tabular}




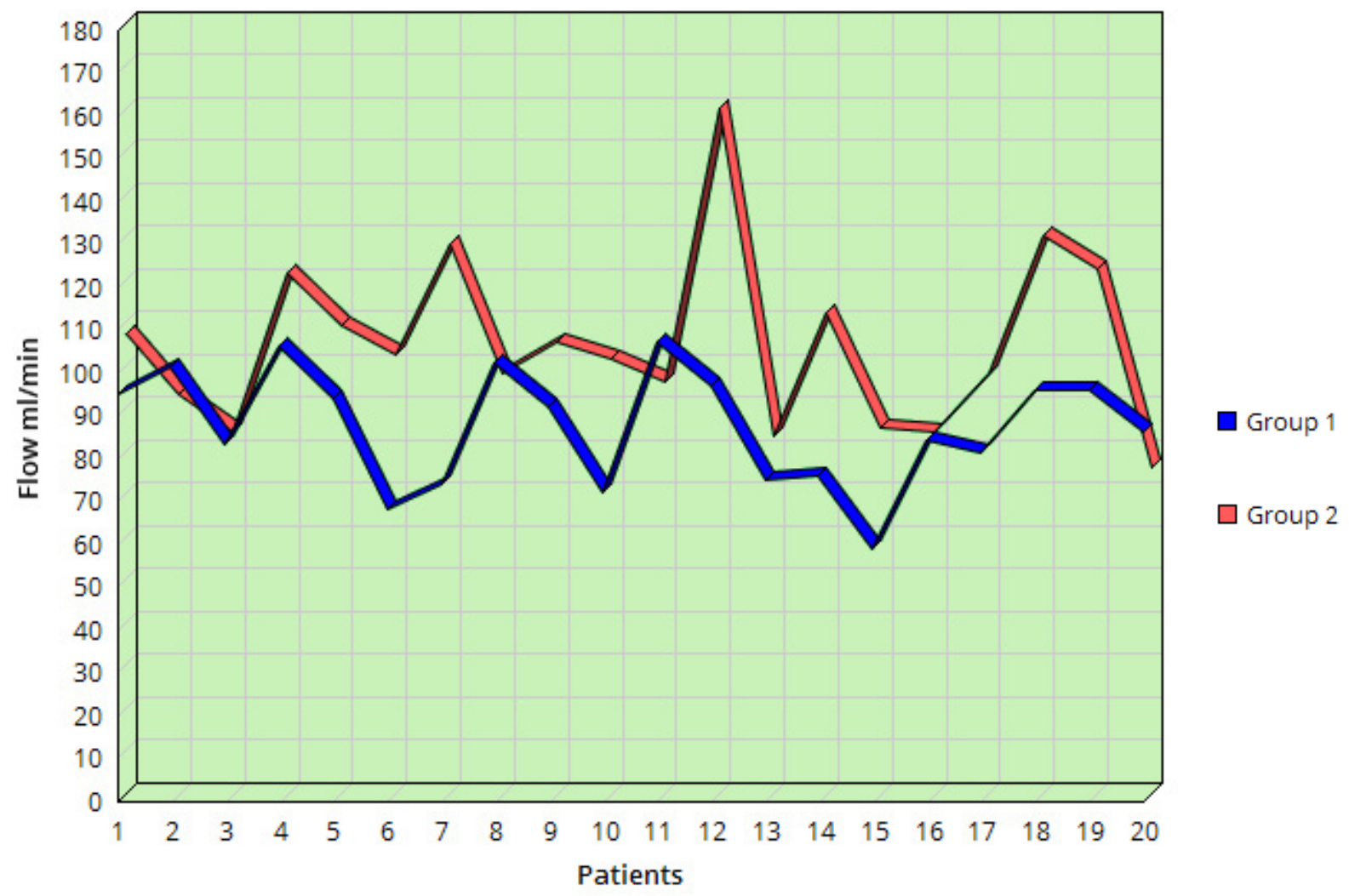

Fig. 2 - Graph depicting the distribution of flow in Group 1 and Group 2 after papaverine application.

harvesting during CABG. We have used various vasodilators to either prevent or treat LIMA spasm, but the best agent is not known yet ${ }^{[11-13]}$. Clinically, papaverine is the most commonly studied and used vasodilator drug. Papaverine can be delivered by various ways, like injection into endothoracic fascia before LIMA dissection, pedicled perivascular injection, topical spray, and intraluminal administration with or without hydrostatic dilation. Few studies have shown that the intraluminal administration type of delivery improves LIMA flow very drastically ${ }^{[14]}$, but it is associated with mechanical injury to the lumen of the mammary artery causing dissections and medial disruption ${ }^{[9,10]}$. A study done by Hausmann ${ }^{[13]}$ reported no difference in LIMA flow when papaverine was delivered intraluminally or injected in the pedicle after LIMA dissection. Papaverine injection into endothoracic fascia before LIMA dissection is associated with few complications, like damage to the vessel wall, making it not usable. Perivascular injection and topical spray are the methods with very minimal chances of injuring LIMA. The perivascular injection delivery method allows better availability of papaverine to the LIMA than the topical spray method. This injection method helps in achieving prolonged exposure of papaverine to LIMA. Transit time flow measurement is a most valuable and accurate method of measuring the blood flow through the grafts ${ }^{[13]}$. In our study, LIMA flow in Group 1 was statistically different from Group 2. Papaverine dosage used in the literature has varied from 0.3 $\mathrm{mg} / \mathrm{mL}$ to $1.5 \mathrm{mg} / \mathrm{mL}$ and to a maximum of $50 \mathrm{mg}^{[14]}$. We used papaverine with a $0.3 \mathrm{mg} / \mathrm{ml}$ concentration. Papaverine delivery to the LIMA pedicle after LIMA dissection definitely improves the flow volume. We observed that administering papaverine by perivascular injection method helps in achieving high flows when compared to the spray method.

\section{CONCLUSION}

Papaverine delivery to LIMA by perivascular injection method provided statistically significant higher flow when compared to the topical spray method. Hence, perivascular delivery of papaverine is more efficient than the spray method in improving LIMA blood flow. 


\section{Authors' roles \& responsibilities}

GGSL Substantial contributions to the conception or design of the work; or the acquisition, analysis, or interpretation of data for the work; drafting the work or revising it critically for important intellectual content; agreement to be accountable for all aspects of the work in ensuring that questions related to the accuracy or integrity of any part of the work are appropriately investigated and resolved; final approval of the version to be published

JKHV Agreement to be accountable for all aspects of the work in ensuring that questions related to the accuracy or integrity of any part of the work are appropriately investigated and resolved; final approval of the version to be published

VGS Drafting the work or revising it critically for important intellectual content; agreement to be accountable for all aspects of the work in ensuring that questions related to the accuracy or integrity of any part of the work are appropriately investigated and resolved; final approval of the version to be published

AKM Agreement to be accountable for all aspects of the work in ensuring that questions related to the accuracy or integrity of any part of the work are appropriately investigated and resolved; final approval of the version to be published

MCN Final approval of the version to be published

\section{REFERENCES}

1. Scott R, Blackstone EH, McCarthy PM, Lytle BW, Loop FD, White JA, et al. Isolated bypass grafting of the left internal thoracic artery to the left anterior descending coronary artery: late consequences of incomplete revascularization. JThorac Cardiovasc Surg. 2000;120(1):173-84. doi:10.1067/ mtc.2000.107280.
2. Sarabu MR, McClung JA, Fass A, Reed GE. Early postoperative spasm in left internal mammary artery bypass grafts. Ann Thorac Surg. 1987;44(2):199200. doi:10.1016/s0003-4975(10)62041-3.

3. Mills NL, Bringaze WL 3rd. Preparation of the internal mammary artery graft. Which is the best method? J Thorac Cardiovasc Surg. 1989;98(1):737; discussion 78-9.

4. Girard DS, Sutton JP 3rd, Williams TH, Crumbley AJ 3rd, Zellner JL, Kratz $J \mathrm{M}$, et al. Papaverine delivery to the internal mammary artery pedicle effectively treats spasm. Ann Thorac Surg. 2004;78(4):1295-8. doi:10.1016/j. athoracsur.2004.01.061.

5. Vilandt J, Kjaergård H, Aggestrup S, Andreasen JJ, Olesen A. Intraluminal papaverine with $\mathrm{pH} 3$ doubles blood flow in the internal mammary artery. Scand Cardiovasc J. 1999;33(6):330-2. doi:10.1080/14017439950141371.

6. Bilgen F, Yapici F, Serbetçioğlu A, Tarhan A, Coruh T, Ozler A. Effect of normothermic papaverine to relieve intraoperative spasm of the internal thoracic artery. Ann Thorac Surg. 1996;62(3):769-71. doi:10.1016/s00034975(96)00441-9.

7. Sasson L, Cohen AJ, Hauptmann E, Schachner A. Effect of topical vasodilators on Internal mammary arteries. Ann Thorac Surg. 1995;59(2):494-6. doi:10.1016/0003-4975(94)00896-f.

8. Yorgancioğlu C, Tokmakoğlu H, Günaydin S, Catav Z, Süzer K. An alternative application of sodium nitroprusside to overcome perioperative spasm of the internal thoracic artery. Cardiovasc Surg. 2001;9(1):64-7.

9. Dregelid E, Heldal K, Resch F, Stangeland L, Breivik K, Svendsen E. Dilation of the internal mammary artery by external and intraluminal papaverine application. J Thorac Cardiovasc Surg.1995;1 10(3):697-703. doi:10.1016/ S0022-5223(95)70101-X.

10. Yavuz S, Celkan A, Göncü T, Türk T, Ozdemir IA. Effect of papaverine applications on blood flow of the internal mammary artery. Ann Thorac Cardiovasc Surg. 2001;7(2):84-8.

11. Cooper GJ, Wilkinson GA, Angelini GD. Overcoming perioperative spasm of the internal mammary artery: which is the best vasodilator? J Thorac Cardiovasc Surg. 1992;104(2):465-8.

12. Huraux C, Makita T, Montes F, Szlam F, Levy JH. A comparative evaluation of the effects of multiple vasodilators on human internal mammary artery. Anesthesiology. 1998;88(6):1654-9. doi:10.1097/00000542-199806000-00030.

13. Hausmann H, Photiadis J, Hetzer R. Blood flow in the internal mammary artery after the administration of papaverine during coronary artery bypass grafting. Tex Heart Inst J. 1996;23(4):279-83.

14. Amin S, Werner RS, Madsen PL, Krasopoulos G, Taggart DP. Influence of coronary territory on flow profiles of saphenous vein grafts. J Cardiothorac Surg. 2018;13(1):23. doi:10.1186/ s13019-018-0709-6. 